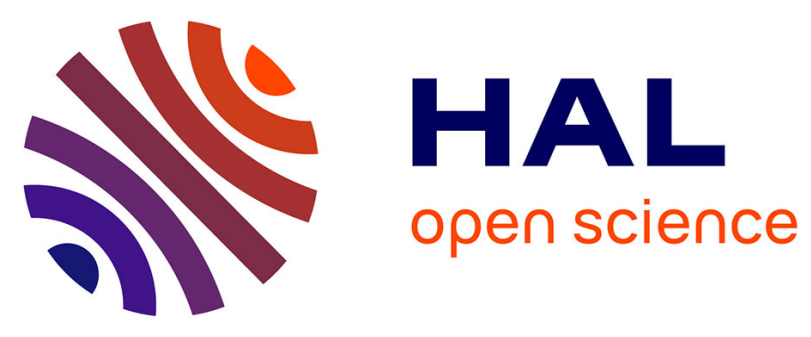

\title{
Towards a Stronger Halogen Bond Involving Astatine: Unexpected Adduct with Bu3PO Stabilized by Hydrogen Bonding
}

Lu Liu, Ning Guo, Julie Champion, Jérôme Graton, Gilles F Montavon, Nicolas Galland, Rémi Maurice

\section{To cite this version:}

Lu Liu, Ning Guo, Julie Champion, Jérôme Graton, Gilles F Montavon, et al.. Towards a Stronger Halogen Bond Involving Astatine: Unexpected Adduct with Bu3PO Stabilized by Hydrogen Bonding. Chemistry - A European Journal, 2020, 26 (17), pp.3713-3717. 10.1002/chem.201905389 . hal03095955

\section{HAL Id: hal-03095955 https://hal.science/hal-03095955}

Submitted on 2 Aug 2021

HAL is a multi-disciplinary open access archive for the deposit and dissemination of scientific research documents, whether they are published or not. The documents may come from teaching and research institutions in France or abroad, or from public or private research centers.
L'archive ouverte pluridisciplinaire HAL, est destinée au dépôt et à la diffusion de documents scientifiques de niveau recherche, publiés ou non, émanant des établissements d'enseignement et de recherche français ou étrangers, des laboratoires publics ou privés. 


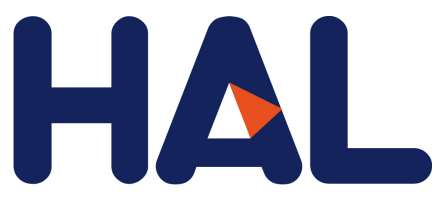

archives-ouvertes

\section{Towards a Stronger Halogen Bond Involving Astatine: Unexpected Adduct with Bu_3PO Stabilized by Hydrogen Bonding}

Lu Liu, Ning Guo, Julie Champion, Jérôme Graton, Gilles Montavon, Nicolas Galland, Rémi Maurice

\section{To cite this version:}

Lu Liu, Ning Guo, Julie Champion, Jérôme Graton, Gilles Montavon, et al.. Towards a Stronger Halogen Bond Involving Astatine: Unexpected Adduct with Bu_3PO Stabilized by Hydrogen Bonding. Chem.Eur.J., 2020, 26 (17), pp.3713-3717. 10.1002/chem.201905389 . hal-02542881

\section{HAL Id: hal-02542881 \\ https://hal.archives-ouvertes.fr/hal-02542881}

Submitted on 6 Nov 2020

HAL is a multi-disciplinary open access archive for the deposit and dissemination of scientific research documents, whether they are published or not. The documents may come from teaching and research institutions in France or abroad, or from public or private research centers.
L'archive ouverte pluridisciplinaire HAL, est destinée au dépôt et à la diffusion de documents scientifiques de niveau recherche, publiés ou non, émanant des établissements d'enseignement et de recherche français ou étrangers, des laboratoires publics ou privés. 


\title{
Towards a stronger halogen bond involving astatine: unexpected adduct with $\mathrm{Bu}_{3} \mathrm{PO}$ stabilized by hydrogen bonding
}

Lu Liu, ${ }^{[a]}$ Ning Guo, ${ }^{[a]}$ Julie Champion, ${ }^{[a]}$ Jérôme Graton, ${ }^{[b]}$ Gilles Montavon, ${ }^{[a]}$ Nicolas Galland ${ }^{*[\mathrm{~b}]}$ and Rémi Maurice*[a]

\author{
[a] L. Liu, Dr. N. Guo, Dr. J. Champion, Dr. G. Montavon, Dr. R. Maurice \\ SUBATECH, IMT Atlantique/CNRS/Université de Nantes \\ 4 rue Alfred Kastler, BP 20722, 44307 Nantes Cedex 3, France \\ E-mail: remi.maurice@subatech.in2p3.fr \\ [b] Dr. J. Graton, Dr. N.Galland \\ CEISAM, Université de Nantes \\ 2 rue de la Houssinière, BP 92208, 44322 Nantes Cedex 3, France
}

E-mail: nicolas.galland@univ-nantes.fr

Supporting information for this article is given via a link at the end of the document.

\begin{abstract}
The halogen bond is a powerful tool for the molecular design, and pushing the limits of its strength is of major interest. Bearing the most potent halogen-bond donor atom, astatine monoiodide (Atl) was recently successfully probed [Nature Chemistry 2018, 10, 428-434]. In this work, we continue the exploration of adducts between Atl and Lewis bases with the tributylphosphine oxide $\left(\mathrm{Bu}_{3} \mathrm{PO}\right)$ ligand, revealing the unexpected experimental occurrence of two distinct chemical species with 1:1 and 1:2 stoichiometries. The $1: 1 \mathrm{Bu}_{3} \mathrm{PO}$...Atl complex is found to exhibit the strongest astatinemediated halogen bond so far (with a formation constant of $10^{4.24 \pm 0.35}$ ). Quantum chemical calculations unveil the intriguing nature of the 1:2 $2 \mathrm{Bu}_{3} \mathrm{PO}$...Atl adduct, involving a halogen bond between Atl and one $\mathrm{Bu}_{3} \mathrm{PO}$ molecular unit plus $\mathrm{CH} \cdots \mathrm{O}$ hydrogen bonds chelating the second $\mathrm{Bu}_{3} \mathrm{PO}$ unit.
\end{abstract}

With the ultimate aim of controlling the stability and properties of molecules and materials, it is of fundamental interest for chemists to improve the understanding of intermolecular interactions and to explore their strength limits. Among the non-covalent interactions available in the chemist's toolkit, the halogen bond $(X B)$ has been recognized to be strongly impactful in various fields such as organocatalysis, drug design in biochemistry and medicinal chemistry, crystal engineering and production of liquid crystals. ${ }^{[1-}$ 5] In short, XBs are attractive and highly directional interactions between an electrophilic region (called $\sigma$-hole) of a halogenated $\mathrm{R}-\mathrm{X}$ compound (called XB donor) and a Lewis base (called XB acceptor). ${ }^{[6]}$ To establish the propensity of $X B$ acceptors to engage in XBs, Laurence et al. introduced in 2011 the diiodine basicity scale $\left(\mathrm{p} K_{\mathrm{BI} 2}\right),{ }^{[7]}$ based on complexation constants measured in organic solution between a reference XB donor $\left(I_{2}\right)$ and a large set of Lewis bases.

Among the halogen elements, astatine (At, $Z=85$ ) is the heaviest naturally occurring one, and it has been predicted to be the strongest $X B$ donor atom, ${ }^{[8-10]}$ despite the persistent lack of experimental data. However, we have recently evidenced the very first XBs involving At via the formation of adducts between astatine monoiodide (Atl) and several Lewis bases. ${ }^{[11]}$ The comparison between the measured equilibrium constants (log $\left.K_{\mathrm{BAt}}\right)$ and the available $\mathrm{p} K_{\mathrm{B} 2}$ values for the same Lewis bases, disclosed a quasi-proportional relationship:

$\log K_{\mathrm{BAtl}} \approx 1.56(22) \times \mathrm{p} K_{\mathrm{B} I 2}$
Hence, Atl indeed appears as a stronger XB donor than $I_{2}$, even though a limited set of Lewis bases has been investigated so far. It is of prime importance to reach the strongest possible XBs involving the astatine element.

To this end, both the XB donors and acceptors may be varied, although the relevant options are severely limited by experimental constraints. On the one hand, even though other halides such as $\mathrm{AtBr}$ and $\mathrm{AtCl}$ are expected to lead to even stronger donor abilities than $A t l,{ }^{[12]}$ the experimental limitations coming from their narrow predominance domain s $^{[13]}$ cause a great challenge to evidence further XB interactions. On the other hand, the selection of Lewis bases is also quite limited. First, the ligands must be stable enough in the acidic and oxidizing conditions which allow the appearance of the Atl species. Accordingly, nitrogen Lewis bases, such as amines, pyridines, anilines, guanidines or imines, should be avoided due to the protonation of the acceptor site under the applied conditions. Second, the ligands must be soluble in an organic solvent. Third, the ligands should have a good affinity for $I_{2}$, which eventually leads to a large $K_{B A t l}$ value.

For this purpose, tributylphosphine oxide $\left(\mathrm{Bu}_{3} \mathrm{PO}\right)$ has been selected as a potential candidate, actually displaying a $p K_{\mathrm{B} \mid 2}$ value of 2.75. ${ }^{[7]}$ According to the equation (1), a larger $K_{\text {BAtl }}$ constant than what has been reported so far $\left(4.01 \pm 0.31\right.$ for $\left.\mathrm{Et}_{2} \mathrm{~S}^{[11]}\right)$ is anticipated. Although this may not be the ultimate ligand for maximizing the $\mathrm{XB}$ bond strength, we focus on this sole ligand that has led to a very unexpected behavior: the occurrence of two adducts (vide infra).

Actually, astatine is the rarest natural element on Earth and, as a radioelement, all of its isotopes are short-lived $\left(\mathrm{t}_{1 / 2} \leq 8.1 \mathrm{~h}\right) \cdot{ }^{[14]}$ It can be artificially produced via nuclear reactions, but in minute quantities, limiting experimental investigations to the ultra-trace scale (concentrations below $10^{-10} \mathrm{~mol} \mathrm{~L}^{-1}$ ). Consequently, conventional spectroscopic tools are unsuited to get experimental information at the molecular level, which can fortunately be obtained by molecular modeling tools. In fact, at ultra-trace concentration, only "indirect" experimental method, based for instance on electromobility, chromatography, or competition, can be used. ${ }^{[15-19]}$

In this work, the liquid/liquid competition method has been applied. The underlying principle is to track the radioactivity distribution between two immiscible phases as a function of the experimental conditions. A variation of the distribution reveals an astatine 
speciation change in at least one of the two phases. ${ }^{[11,20]}$ Here, a cyclohexane solution of $\mathrm{Bu}_{3} \mathrm{PO}$ was mixed with an aqueous solution containing $0.05 \mathrm{~mol} \mathrm{~L}^{-1} \mathrm{HClO}_{4}$ and $\mathrm{Nal}$, doped with ${ }^{211} \mathrm{At}$. For a series of experiments, the Nal concentration was kept fixed while the $\mathrm{Bu}_{3} \mathrm{PO}$ concentration in the organic phase was increased. These two phases were well mixed by shaking for 2 hours to reach the reaction equilibrium, and were separated afterwards. An aliquot of each phase was then taken to measure the radioactivity by a liquid scintillation counter.

The distribution coefficient of astatine $(D)$ is defined as the ratio between the volumetric radioactivity in the organic and aqueous phases. Considering the $\mathrm{p} K_{\mathrm{a}}$ value of $\mathrm{HI}(-9.5)$, dissolved $\mathrm{Nal}$ salt releases $100 \%$ of the ionic species $\mathrm{I}$. Under the experimental conditions (see $\mathrm{SI}$ ), $\mathrm{At}^{+}$is the predominant astatine species and it readily reacts with $\mathrm{I}^{-}{ }^{[20,21]}$ The selected $\mathrm{I}^{-}$concentration range (from 0.01 to $0.2 \mathrm{~mol} \mathrm{~L}^{-1}$ ) ensures that Atl and $\mathrm{Atl}_{2}{ }^{-}$initially predominate in the aqueous phase. In contrast to $\mathrm{Atl}_{2}{ }^{-}$, Atl can be significantly extracted towards the organic phase, hence being the only species able to interact with $\mathrm{Bu}_{3} \mathrm{PO}$ in the organic phase. Thermodynamic models, based on the key equilibria at play in this biphasic system, are tested to reproduce the experimental $D$ values. Three experimental cases with $\left[\mathrm{I}^{-}\right]=0.01,0.1$, and $0.2 \mathrm{~mol}$ $\mathrm{L}^{-1}$ are displayed in Figure 1 to illustrate our procedure to establish the best fitting model. In all the cases, $D$ is practically constant below $10^{-4} \mathrm{~mol} \mathrm{~L}^{-1}$ of $\mathrm{Bu}_{3} \mathrm{PO}$. From $10^{-4}$ to $10^{-2} \mathrm{~mol} \mathrm{~L}^{-1}, D$ increases sharply with a maximal slope depending on the added $\mathrm{I}$ concentration. The increase in $D$ is finally slowing down at higher $\mathrm{Bu}_{3} \mathrm{PO}$ concentrations.
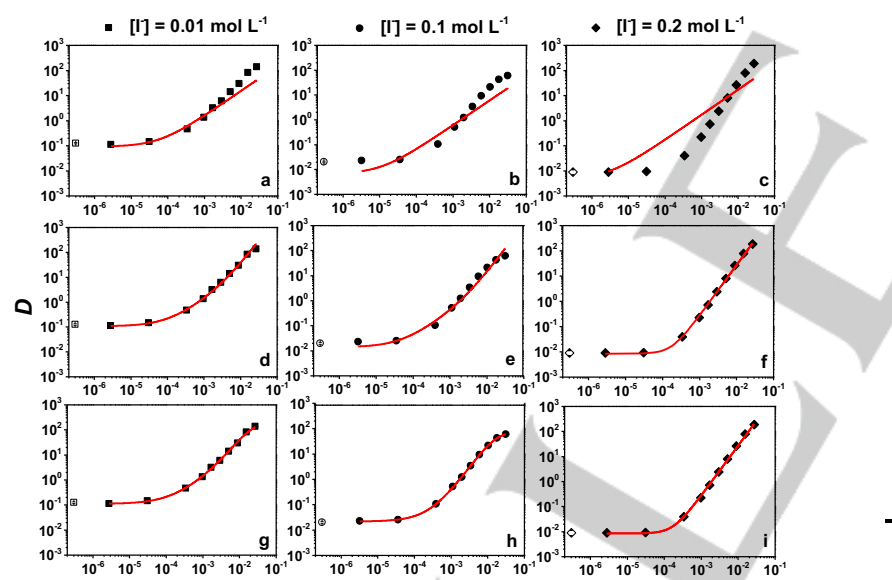

$\left[B u_{3} P O\right] / \mathrm{mol} \mathrm{L}^{-1}$
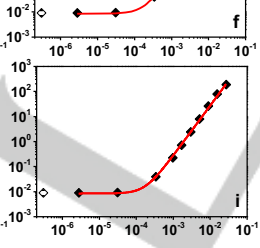

Figure 1. Astatine distribution coefficient between the organic and aqueous phases as a function of $\mathrm{Bu}_{3} \mathrm{PO}$ and $\mathrm{I}^{-}$concentrations. The hollow symbols indicate data without $\mathrm{Bu}_{3} \mathrm{PO}$. Data fitted with $(\mathrm{a}, \mathrm{b}, \mathrm{c})$ model 1 , considering the formation of the $1: 1 \mathrm{Bu}_{3} \mathrm{PO}$...Atl adduct in the organic phase, (d, e, f) model 2 , also allowing the formation of the $1: 22 \mathrm{Bu}_{3} \mathrm{PO} \ldots$ Atl adduct, $(\mathrm{g}, \mathrm{h}, \mathrm{i})$ model 3 , considering in addition the partial solubility of the $1: 2$ adduct in the aqueous phase.

For all the considered cases, $\mathrm{Atl}_{2}^{-}$is the initial predominant astatine species in the aqueous phase. ${ }^{\left[{ }^{[1]}\right.}$ Its formation from Atl is ruled by reaction (2), with a previously determined equilibrium constant $K\left(10^{2.7 \pm 0.3}\right.$ at zero ionic strength). ${ }^{[21]}$ The partitions of $\mathrm{Bu}_{3} \mathrm{PO}$ and Atl in the two phases are taken into account via equilibria (3) and (4), overlined species relating to the organic phase. $D_{1}\left(10^{0.02 \pm 0.02}\right)$ has been determined from total organic carbon (TOC) measurements in the absence of astatine, while $D_{2}$ is a parameter adjusted during the fitting process. In the organic phase, all the models consider the formation of the expected $1: 1$ complex via reaction (5).

$$
\begin{aligned}
& \mathrm{Atl}+\mathrm{I}^{-} \stackrel{K}{\rightleftharpoons} \mathrm{Atl}_{2}^{-} \quad K=\frac{\left[\mathrm{Atl}_{2}^{-}\right]}{[\mathrm{Atl}] \times\left[I^{-}\right]} \\
& \mathrm{Bu}_{3} \mathrm{PO} \stackrel{D_{1}}{\rightleftharpoons} \overline{\mathrm{Bu}_{3} \mathrm{PO}} \quad D_{1}=\frac{\left[\overline{\left.\mathrm{Bu}_{3} \mathrm{PO}\right]}\right.}{\left[\mathrm{Bu}_{3} \mathrm{PO}\right]} \\
& \mathrm{Atl} \stackrel{D_{2}}{\rightleftharpoons} \overline{\mathrm{Atl}} \quad D_{2}=\frac{[\overline{\mathrm{Atl}}]}{[\mathrm{Atl}]} \\
& \overline{\mathrm{Bu}_{3} \mathrm{PO}}+\overline{\mathrm{Atl}} \stackrel{K_{\mathrm{BAtl}}}{\rightleftharpoons} \overline{\mathrm{Bu}_{3} \mathrm{PO} \cdots \mathrm{Atl}} \quad K_{\mathrm{BAtl}}=\frac{\overline{\left.\mathrm{Bu}_{3} \mathrm{PO} \cdots \mathrm{Atl}\right]}}{\left[\mathrm{Bu}_{3} \mathrm{PO}\right] \times[\mathrm{Att}]}
\end{aligned}
$$

With these equations, an analytical expression of $D$ can be derived (model 1, see SI). The experimental data was then fitted with $D_{2}$ and $K_{\mathrm{BAtl}}$ as adjustable parameters, in a way that is similar to the previous seminal study. ${ }^{[11]}$ However, this model fails to properly describe the experimental behavior (Figure $1 \mathrm{a}, \mathrm{b}, \mathrm{c}$ ). The unexplained $D$ increase, corresponding to a stronger astatine transfer towards the organic phase, suggests the presence of another extractable astatine species. Under the experimental conditions, the most probable hypothesis is that Atl and $\mathrm{Bu}_{3} \mathrm{PO}$ can form a complex of different stoichiometry. Owing to the extremely low astatine concentration, we assume that a 1:2 adduct with $2 \mathrm{Bu}_{3} \mathrm{PO}$ equivalents occurs in the organic phase via reaction (6):

$$
2 \overline{\mathrm{Bu}_{3} \mathrm{PO}}+\overline{\mathrm{Atl}} \stackrel{K_{\mathrm{B} 2 \mathrm{Atl}}}{\rightleftharpoons} \overline{2 \mathrm{Bu}_{3} \mathrm{PO} \cdots \mathrm{Atl}} \quad K_{\mathrm{B} 2 \mathrm{Atl}}=\frac{\left[\overline{2 \mathrm{Bu}_{3} \mathrm{PO} \cdots \mathrm{Atl}}\right]}{\left[\overline{\left.\mathrm{Bu}_{3} \mathrm{PO}\right]^{2} \times[\overline{\mathrm{Atl}}]}\right.}
$$

Based on equations (2)-(6), model 2 leads to significantly improved fitted results (Figure $1 \mathrm{~d}$, e, f), despite some imperfections observed at the highest ligand concentrations. The slight $D$ overestimation may imply that some of the formed species, such as $\mathrm{Bu}_{3} \mathrm{PO} \cdots$ Atl or $2 \mathrm{Bu}_{3} \mathrm{PO} \cdots$ Atl, could be backextracted towards the aqueous phase. Visual adjustments suggest that with the additional hypothesis of the partial solubility of $2 \mathrm{Bu}_{3} \mathrm{PO} \cdots$ Atl (equation (7)), the most refined model 3 best fits all the experimental results (Figure $1 \mathrm{~g}, \mathrm{~h}, \mathrm{i}$ ).

$$
2 \mathrm{Bu}_{3} \mathrm{PO} \cdots \mathrm{Atl} \stackrel{D_{3}}{\rightleftharpoons} \overline{2 \mathrm{Bu}_{3} \mathrm{PO} \cdots \mathrm{Atl}} \quad D_{3}=\frac{\left[\overline{2 \mathrm{Bu}_{3} \mathrm{PO} \cdots \mathrm{Atl}}\right]}{\left[2 \mathrm{Bu}_{3} \mathrm{PO} \cdots \mathrm{Atl}\right]}
$$

Table 1. Formation constants of $\mathrm{Atl}$ and $\mathrm{Bu}_{3} \mathrm{PO}$ adducts, obtained from the distribution coefficients fitting with model 3.

\begin{tabular}{ccc}
\hline $\begin{array}{c}\left.\mathrm{I}^{-}\right] \\
\left(\mathrm{mol} \mathrm{L}^{-1}\right)\end{array}$ & $\log K_{\mathrm{BAtl}}{ }^{[\mathrm{a}]}$ & $\log K_{\mathrm{B} 2 \mathrm{Atl}}{ }^{[\mathrm{a}]}$ \\
\hline 0.01 & $4.41 \pm 0.12$ & $7.47 \pm 0.12$ \\
0.1 & $4.19 \pm 0.14$ & $8.03 \pm 0.06$ \\
0.2 & $-28.83^{[\mathrm{b}]}$ & $8.44 \pm 0.34$ \\
\hline
\end{tabular}

[a] Uncertainties correspond to 95\% confidence intervals. [b] Unreliable.

The formation constants of the $1: 1$ and $1: 2$ adducts can now be derived from model 3 , gathering the values extracted from all the measurements (Table 1 and S2). Note that for $\left[\mathrm{I}^{-}\right]=0.2 \mathrm{~mol} \mathrm{~L}^{-1}$, the formation of the 1:1 complex does not play a significant role in the adjustment: the quality of the fit is maintained in a large interval of $K_{B A t l}$ value that we imposed (including the average value obtained from other I' concentrations), so does the adjusted value of $K_{\mathrm{B} 2 \mathrm{Atl}}$. Therefore, the formation constants for the 1:1 
complex at the highest $\mathrm{I}^{-}$concentration are excluded. Finally, the average equilibrium constant values are $\log K_{\text {BAtl }}=4.24 \pm 0.35$ and $\log K_{\mathrm{B} 2 \mathrm{Atl}}=7.95 \pm 0.72$.

Since the experimental approach can only give information at the macroscopic scale, quantum chemistry methods represent an appealing alternative to establish the nature of the formed species Indeed, the molecular structure(s) can readily be determined from the (experimental) stoichiometry of a compound, as well as many other spectroscopic signatures at a desired level of accuracy. In this work, the two-component relativistic density functional theory (DFT) approach is used, as in previous successful works. ${ }^{[11,22]}$ According to the former benchmark study focused on astatine species, the B3LYP hybrid functional appears as a safe costeffective choice, ${ }^{[23]}$ which is also true for describing astatinemediated halogen bonds. ${ }^{[11]}$ The calculated value of log $K_{\mathrm{BAtl}}$ is 4.37 at the B3LYP/AVDZ level of theory, in excellent agreement with the experimental one. Furthermore, a very close value (4.50) was obtained using an alternative exchange-correlation functional of hybrid meta-GGA quality, namely PW6B95, which confirms the reliability of our cost-effective computational approach and the identification of the formed species as an At-mediated $\mathrm{XB}$ complex. Indeed, the most stable structure for the 1:1 adduct is displayed in Figure 2. The two molecular units, Atl and $\mathrm{Bu}_{3} \mathrm{PO}$, interact via the astatine atom and the oxygen of $\mathrm{Bu}_{3} \mathrm{PO}$, with $\mathrm{d}_{\mathrm{At} \ldots \mathrm{O}}$ $=2.606 \AA$. The interaction distance, shorter than the sum of the corresponding van der Waals radii, together with the $\theta_{\circ} \ldots$...t-l angle value close to $180^{\circ}$, constitute typical features of halogen bonding. We can therefore safely conclude that the 1:1 adduct is an XB complex and, interestingly, that it is stabilized by the strongest $X B$ involving astatine ever characterized experimentally.
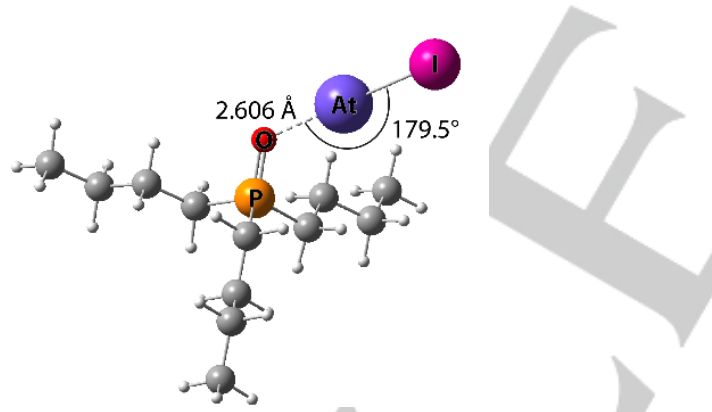

Figure 2. Structure of the most stable 1:1 complex between Atl and $\mathrm{Bu} 3 \mathrm{PO}$ calculated at the B3LYPIAVDZ level of theory.

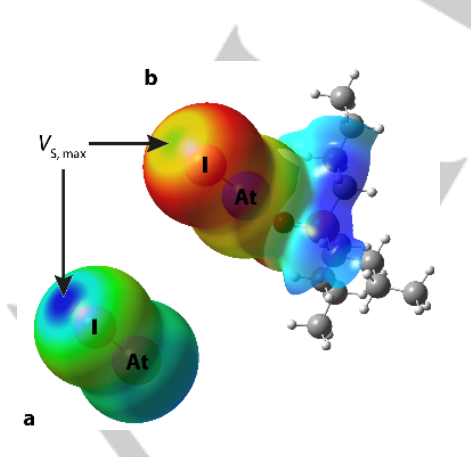

Figure 3. Molecular electrostatic potential calculated at the B3LYP/AVDZ level of theory for (a) Atl and (b) Bu $\mathrm{Bu}_{3} \mathrm{PO}$...Atl. The molecular surfaces were defined by isovalue of the electron density of $0.001 \mathrm{e} \mathrm{bohr}^{-3}$. Color code: from red (most negative values) to blue (most positive values).
Since it is the first time that a 1:2 adduct formed by Atl is observed, several hypotheses about its nature can be formulated. With two halogens in the Atl molecule, the hot question that firstly emerges is whether this adduct exhibits two different XBs. As mentioned at the beginning, the $\sigma$-hole concept can help to rationalize and to anticipate the formation of XB interactions. ${ }^{[24]}$ The $\sigma$-hole can be characterized by computing the molecular electrostatic potential (MEP), as shown in Figure 3 for the Atl and $\mathrm{Bu}_{3} \mathrm{PO}^{\cdots}$ Atl species. In addition to the expected $\sigma$-hole at the astatine atom, ${ }^{[12,25]}$ a $\sigma$ hole can be observed, for Atl monomer, at the iodine site with a local maximum value $\left(V_{\mathrm{s}, \max }\right)$ of $+85 \mathrm{~kJ} \mathrm{~mol}^{-1}$ (Figure $3 \mathrm{a}$ ). However, the MEP of the Atl unit at the I site is drastically altered after formation of the $1: 1$ adduct (Figure $3 \mathrm{~b}$ ). The $V_{\mathrm{s} \text {, max }}$ at the iodine atom even becomes negative, meaning that the $\sigma$-hole is essentially disabled. Hence, the electrophilic site of the iodine atom in Atl is deactivated by the formation of a first XB in the 1:1 complex. It is therefore very unlikely that $\mathrm{Bu}_{3} \mathrm{PO}^{\cdots}$ Atl forms a second $\mathrm{XB}$ with another $\mathrm{Bu}_{3} \mathrm{PO}$ molecule. Conversely, at the $\mathrm{Bu}_{3} \mathrm{PO}^{\cdots}$ Atl molecular surface, the geminal methylene groups appear much more acidic (a marked blue color indicating more electrophilic sites). Thus, the second $\mathrm{Bu}_{3} \mathrm{PO}$ molecule would preferentially interact through hydrogen bonds involving polarized $\mathrm{CH}_{2}$ groups of the first $\mathrm{Bu}_{3} \mathrm{PO}$ molecule, rather than through halogen bonding.

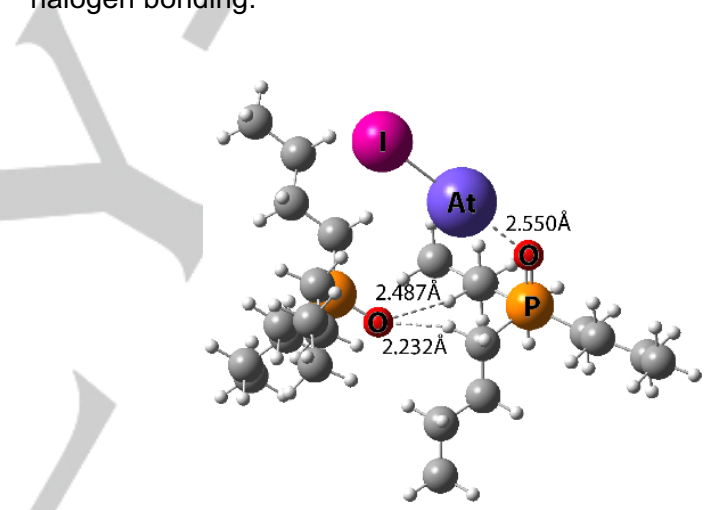

Figure 4. Structure of the most stable 1:2 adduct between Atl and $\mathrm{Bu}_{3} \mathrm{PO}$ calculated at the B3LYP/SVPD level of theory.

This hypothesis was thoroughly assessed by starting a search for possible structures of the 1:2 adduct. A slightly less sophisticated computational methodology, B3LYP/SVPD, was used due to the number and the size of considered chemical systems, at the expense of a moderate lessening of accuracy. Actually, the log $K_{B A t l}$ value for the $1: 1$ complex is 4.54 at this lower level of theory, which remains (i) close to the previous B3LYP/AVDZ value of 4.37 , and (ii) in fair agreement with the measured one $(4.24 \pm 0.35)$. Hence, a reasonable accuracy is achieved at the B3LYP/SVPD level of theory. The most stable 1:2 adduct structure from the B3LYP/SVPD calculations (Figure 4) discloses (i) a halogen bond as described above, and (ii) two chelating hydrogen bonds involving the oxygen atom of the second $\mathrm{Bu}_{3} \mathrm{PO}$ unit and two geminal $\mathrm{C}-\mathrm{H}$ bonds of the first $\mathrm{Bu}_{3} \mathrm{PO}$ unit. The interaction distances associated with the two hydrogen bonds, 2.232 and $2.487 \AA$, are significantly shorter than the sum of $\mathrm{O}$ and $\mathrm{H}$ van der Waals radii, while the XB appears slightly strengthened. Another strong support for this structure comes from the energy criterion: this structure is stabilized by about $25 \mathrm{~kJ} \mathrm{~mol}^{-1}$ while the formation of a second $\mathrm{XB}$ with the $\mathrm{I}$ atom would yield about $1 \mathrm{~kJ} \mathrm{~mol}^{-1}$ of 
stabilization. This firmly supports the occurrence of the $2 \mathrm{Bu}_{3} \mathrm{PO}^{\cdots}$ Atl structure, rather than the $\mathrm{Bu}_{3} \mathrm{PO} \ldots \mathrm{Atl} \ldots \mathrm{OPBu}_{3}$ adduct. Moreover, it is worth noting that a binding energy of $25 \mathrm{~kJ} \mathrm{~mol}^{-1}$, corresponding to a value of 4.38 in log units at $298 \mathrm{~K}$, is consistent with the experimental stepwise constant $(3.71 \pm 1.07)$ for the formation of the 1:2 adduct from the 1:1 one.

In the present work, two adducts of Atl and $\mathrm{Bu}_{3} \mathrm{PO}$ have been evidenced by a coupled experimental and computational approach. The 1:1 adduct, $\mathrm{Bu}_{3} \mathrm{PO} \cdots \mathrm{Atl}$, reveals the strongest $\mathrm{XB}$ involving astatine ever characterized, with a formation constant of $10^{4.24 \pm 0.35}$. The $1: 2$ adduct, $2 \mathrm{Bu}_{3} \mathrm{PO} \cdots$ Atl, with a global formation constant of $10^{7.95 \pm 0.72}$, is the first adduct of its kind identified to date The nature of these adducts has been established by means of relativistic DFT calculations, showing that the 1:1 complex is indeed a halogen bonded one while the 1:2 adduct is stabilized by one halogen bond plus two hydrogen bonds sticking together the two Lewis bases. Therefore, we confirm the unique power of quantum chemistry methods, as virtual spectroscopes, to scrutinize astatine species. Our experience indicates that, in view of attempting to form a 1:2 adduct ruled by two halogen bonds, a first strong $X B$ with a Lewis base deactivates the iodine XB donor site of Atl. Nevertheless, it will be extremely difficult with moderate $\mathrm{XB}$ acceptors to experimentally distinguish the 1:1 complex from the $1: 2$ one. Such a study will naturally require strong input from computational modeling.
[13] J. Champion, M. Seydou, A. Sabatié-Gogova, E. Renault, G. Montavon, N. Galland, Phys. Chem. Chem. Phys. 2011, 13, 14984-14992.

[14] D. S. Wilbur, Nat. Chem. 2013, 5, 246.

[15] R. Dreyer, I. Dreyer, S. Fischer, H. Hartmann, Radioanal. Nucl. Chem. Lett. 1985, 96, 333-342.

[16] N. Guo, F. Pottier, J. Aupiais, C. Alliot, G. Montavon, J. Champion, Inorg. Chem. 2018, 57, 4926-4933.

[17] D. C. Sergentu, D. Teze, A. Sabatié-Gogova, C. Alliot, N. Guo, F. Bassal, I. Da Silva, D. Deniaud, R. Maurice, J. Champion, et al., Chem. - A Eur. J. 2016, 22, 2964-2971.

[18] A. Sabatié-Gogova, J. Champion, S. Huclier, N. Michel, F. Pottier, N. Galland, Z. Asfari, M. Chérel, G. Montavon, Anal. Chim. Acta 2012, 721, 182-188.

[19] J. Champion, C. Alliot, S. Huclier, D. Deniaud, Z. Asfari, G. Montavon, Inorganica Chim. Acta 2009, 362, 2654-2661.

[20] J. Champion, C. Alliot, E. Renault, B. M. Mokili, M. Chérel, N. Galland, G. Montavon, J. Phys. Chem. A 2010, 114, 576-582.

[21] N. Guo, D. C. Sergentu, D. Teze, J. Champion, G. Montavon, N. Galland, R. Maurice, Angew. Chem. Int. Ed. 2016, 55, 15369-15372.

[22] S. Sarr, J. Graton, G. Montavon, J. Pilmé and N. Galland, ChemPhysChem, accepted: DOI: 10.1002/cphc.201901023.

[23] D. C. Sergentu, G. David, G. Montavon, R. Maurice, N. Galland, J. Comput Chem. 2016, 37, 1345-1354.

[24] P. Politzer, J. S. Murray, T. Clark, Phys. Chem. Chem. Phys. 2013, 15, 11178-11189.

[25] N. Galland, G. Montavon, J. Y. Le Questel, J. Graton, New J. Chem. 2018, 42, 10510-10517.

\section{Acknowledgements}

This work has been supported in part by grants from the French National Agency for Research called "Investissements d'Avenir" (ANR-11-EQPX-0004, ANR-11-LABX-0018). It was carried out using HPC resources from CCIPL ("Centre de Calcul Intensif des Pays de la Loire").

Keywords: astatine $\cdot$ halogen bond $\cdot$ hydrogen bond $\cdot$ competition experiments $\cdot$ relativistic quantum chemical calculations

[1] G. Cavallo, P. Metrangolo, R. Milani, T. Pilati, A. Priimagi, G. Resnati, G. Terraneo, Chem. Rev. 2016, 116, 2478-2601.

[2] F. Meyer, P. Dubois, CrystEngComm 2013, 15, 3058-3071.

[3] S. M. Walter, F. Kniep, E. Herdtweck, S. M. Huber, Angew. Chem. Int. Ed. 2011, 50, 7187-7191.

[4] R. Wilcken, M. O. Zimmermann, A. Lange, A. C. Joerger, F. M. Boeckler, J. Med. Chem. 2013, 56, 1363-1388.

[5] P. Metrangolo, G. Resnati, Chem. Commun. 2013, 49, 1783-1785.

[6] G. R. Desiraju, P. S. Ho, L. Kloo, A. C. Legon, R. Marquardt, P. Metrangolo, P. Politzer, G. Resnati, K. Rissanen, Pure Appl. Chem. 2013, 85, 17111713.

[7] C. Laurence, J. Graton, M. Berthelot, M. J. El Ghomari, Chem. - A Eur. J. 2011, 17, 10431-10444.

[8] J. G. Dojahn, E. C. M. Chen, W. E. Wentworth, J. Phys. Chem. 1996, 100, 9649-9657.

[9] I. Alkorta, F. Blanco, M. Solimannejad, J. Elguero, J. Phys. Chem. A 2008, 112, 10856-10863.

[10] F. Zhou, Y. Liu, Z. Wang, T. Lu, Q. Yang, Y. Liu, B. Zheng, Phys. Chem Chem. Phys. 2019, 21, 15310-15318.

[11] N. Guo, R. Maurice, D. Teze, J. Graton, J. Champion, G. Montavon, N Galland, Nat. Chem. 2018, 10, 428-434.

[12] J. Graton, S. Rahali, J. Y. Le Questel, G. Montavon, J. Pilmé, N. Galland, Phys. Chem. Chem. Phys. 2018, 20, 29616-29624. 


\section{Entry for the Table of Contents}
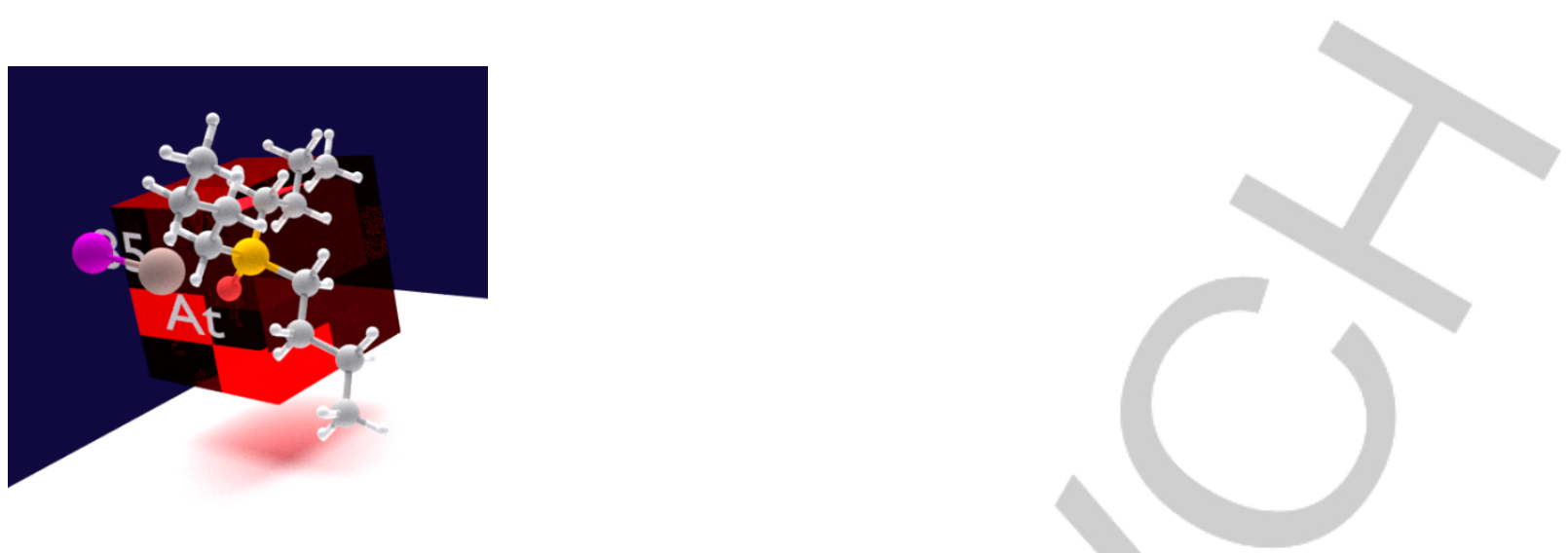

Liu et al. report on two distinct adducts between Atl and $\mathrm{Bu}_{3} \mathrm{PO}$ in their Communication on page xxx ft. These adducts are experimentally and theoretically characterized in terms of equilibrium constants and molecular structures. While the first adduct, Bu $32 \mathrm{PO} \cdots \mathrm{Atl}$, is bound by the strongest halogen-bond so far with Atl, the second adduct $2 \mathrm{Bu}_{3} \mathrm{PO} \cdots$ Atl displays one halogen bond plus two hydrogen bonds between the $\mathrm{Bu}_{3} \mathrm{PO}$ units. 